\title{
BIBECHANA
}

ISSN 2091-0762 (Print), 2382-5340 (Online)

Journal homepage: http://nepjol.info/index.php/BIBECHANA

Publisher: Department of Physics, Mahendra Morang A.M. Campus, TU, Biratnagar, Nepal

\section{Fabrication of open type carbonizer for the preparation of activated carbon from rice husk}

\author{
A. Kumari Dhami, A. Rajbhandari (Nyachhyon)* \\ Central Department of Chemistry, Tribhuvan University, Kirtipur, Nepal \\ *Email: armila3@yahoo.com
}

\section{Article Information:}

Received: May 11, 2020

Accepted: June 9, 2020

Keywords:

Rice husk

Open type carbonizer

Activated carbon

Methylene blue

\begin{abstract}
Activated carbon has been prepared from rice husk using laboratory fabricated open type carbonizer. The raw rice husk powder was named as RRH whereas chemically activated rice husk was named as CARH. Both samples were characterized by methylene blue number (MBN), iodine number (IN) and surface area. The MBN and IN of RRH was found to be $83 \mathrm{mg} / \mathrm{g}$ and $415 \mathrm{mg} / \mathrm{g}$ whereas CARH was $99 \mathrm{mg} / \mathrm{g}$ and $716 \mathrm{mg} / \mathrm{g}$ respectively which indicate the presence of mesoporosity and microporosity of the samples. The surface area of RRH was found to be $206 \mathrm{~m}^{2} / \mathrm{g}$ while CARH was found to be $531 \mathrm{~m}^{2} / \mathrm{g}$. XRD analysis showed that the prepared materials were amorphous with some crystalline state while FTIR spectra showed the presence of different functional groups such as hydroxyl, carbonyl, Si-O-Si bond and aromatic group on the material. The adsorption properties of prepared samples were studied by using Langmuir and Freundlich isotherm models. Langmuir adsorption isotherm model was found to be best fitted. It showed that prepared materials have homogenous surface with monolayer type of adsorption. The maximum monolayer coverage (Qm) for RRH was found to be $55 \mathrm{mg} / \mathrm{g}$ and for CARH 143 $\mathrm{mg} / \mathrm{g}$. Thus, results revealed that laboratory fabricated low cost open type carbonizer is suitable for the preparation of activated carbon.
\end{abstract}

DOI: https://doi.org/10.3126/bibechana.v18i1.28918

This work is licensed under the Creative Commons CC BY-NC License. https://creativecommons.org/licenses/by-nc/4.0/

\section{Introduction}

Activated carbon (AC) is an inimitable form of carbon and is generally prepared from carbonaceous materials. Such materials could be obtained from plant resources including agriculture wastes. Some of the agricultural wastes that have been used are saw dust [1-2], rice husk [3], corncob [4], sugarcane [5], waste tea [6] and other by-product such as; almond shell [7], coconut shell [8], hazelnut shell [9], olive
[10], apricot [11] and cherry stones [12]. Among them rice husk is one of the eco-friendly and locally available agricultural waste that has been generated approximately 120 million tons annually from rice milling industries [13] and hence in present work, rice husk has been used as precursor for the preparation of activated carbon.

Rice husk is actually outer most covering of the rice grain. It contains $15-20 \%$ hemicellulose, $28-30 \%$ 
cellulose, $25-30 \%$ lignin, $15-20 \%$ silica and $10-15 \%$ moisture [14]. Hemicellulose, cellulose and lignin are generally considered as a major source of activated carbon. These AC are generally prepared by carbonization technique. For carbonization, instruments like muffle furnace, tube furnace and other furnaces have been used. The temperature ranges from 100 to $1800^{\circ} \mathrm{C}$. Such high temperature needs high energy consumption and running cost also get elevated. Hence, we tried to fabricate an efficient, low cost open type carbonizer to prepare AC [15]. Thus prepared activated carbon from open type carbonizer was then activated by phosphoric acid which mainly helps in dehydration of lignocellulosic material and formation of phosphate ester linkage between cellulose rings which inhibits shrinkage of structure during heat treatment.

Actually, activation is the way that is employed to increase surface area and porosity from the carbonized organic precursor [16]. The organic precursor consists of elementary crystallites with a large number of interstices between them. These interstices were filled with disorganized carbon residue that blocks the pore entrances due to which low porosity observed.

The highly porous activated carbon with high surface area has got wider application in various fields like to remove pesticides and organic compounds from aqueous solution, to treat waste water, to purify food, beverage, to remove various dyes, for reducing organic chemicals, chlorine, heavy metals, as catalyst carriers (catalytic support) and as adsorbent for air purification [17]. In present work, activated carbon derived from rice husk was used to study the adsorption of methylene blue dye.

\section{Materials and Method}

\section{Reagents}

The reagents such as orthophosphoric acid $\left(\mathrm{H}_{3} \mathrm{PO}_{4}\right)$, methylene blue, iodine used were of analytical grade and procured from Merck Company. All the experiments were carried out in distilled water. Stock solution of methylene blue was prepared by dissolving $1 \mathrm{~g}$ of $\mathrm{MB}$ in $1000 \mathrm{~mL}$ of distilled water in volumetric flask. The $0.1 \mathrm{~N}$ of $\mathrm{I}_{2}$ solutions was prepared by dissolving $1.272 \mathrm{~g}$ of $\mathrm{I}_{2}$ and $5 \mathrm{~g}$ of $\mathrm{KI}$ in
$100 \mathrm{~mL}$ of water and left for $24 \mathrm{hrs}$ for complete dissolution.

\section{Instruments}

The X-Ray Diffractometer (D2-Phaser, Bruker, Germany) has been used to study the phase state of as prepared activated carbon. It was operated at an accelerating voltage of $40 \mathrm{KV}$ and current $40 \mathrm{~mA}$ with $\mathrm{Cu}-\mathrm{K} \alpha$ radiation $\left(\lambda=1.5418 \mathrm{~A}^{\circ}\right)$ in the diffraction angle of 10 to 50 degrees. The surface functional group was studied by Fourier Transmission Infrared Spectroscopy (Shimadzu, Model No. IRTracer-100, Japan). The FTIIR spectra were recorded at 4000-400 $\mathrm{cm}^{-1}$ wave number.

\section{Fabrication of open type carbonizer}

Open Type Carbonizer was fabricated by following procedure:

\section{Step 1: Fabrication of chamber}

First of all, the chamber was prepared by taking a can having $40 \mathrm{~cm}$ height and $20 \mathrm{~cm}$ diameter. It has volume of $20 \mathrm{~L}$. Bottom of the can was removed and a hole was made at the top of the can which has diameter of $10 \mathrm{~cm}$. Then, small holes have been made at the surface of the can at every $10 \mathrm{~cm}$ distance so that, perforated surface have been obtained. The diameter of hole is $2 \mathrm{~cm} \mathrm{[15].} \mathrm{The} \mathrm{structure} \mathrm{of}$ chamber is shown in Fig. 1(a).

\section{Step 2: Fabrication of chimney}

Then a chimney was prepared by taking, $30 \times 122 \mathrm{~cm}$ sized GI sheet. It was folded and clamped together to make a roll having diameter of $10 \mathrm{~cm} \mathrm{[15].} \mathrm{The} \mathrm{figure}$ of chimney is shown in Fig. 1(b).

\section{Step 3: Assemble of chimney and chamber}

As prepared chimney was then assembled with prepared chamber by welding on the top of the chamber having hole of $10 \mathrm{~cm}$ as shown in Fig. 1(c). In this way, open type carbonizer was fabricated.

\section{Preparation of adsorbent}

\section{Preparation of raw rice husk (RRH)}

Raw rice husk (RRH) was collected from rice mill. It was washed with water and allowed to dry in sunlight. After complete dryness, it was grinded into fine powder in an electric grinder and sieved through 
$75 \mu \mathrm{m}$ sized sieve. Thus, obtained powder is named as RRH.
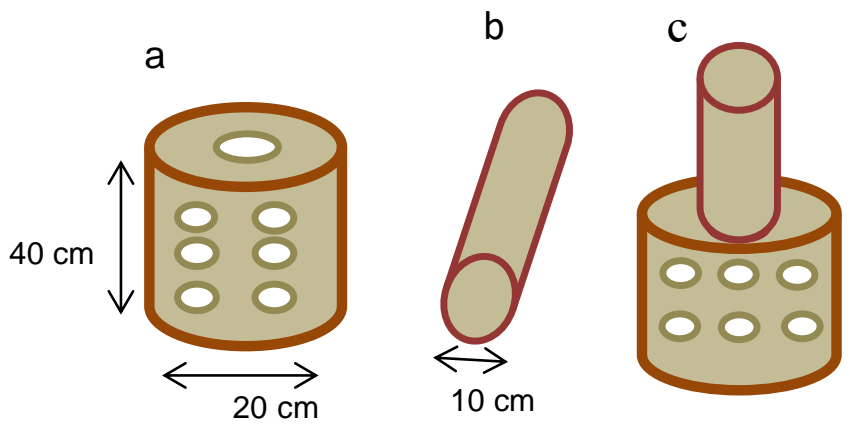

Fig. 1: Fabrication of Open Type Carbonizer.

\section{Preparation of chemically activated rice husk (CARH)}

The rice husk was carbonized in open type carbonizer. Then this carbonized carbon was impregnated with phosphoric acid in the ratio of $\mathrm{H}_{3} \mathrm{PO}_{4} 1: 1$ wt by wt. They were left for $24 \mathrm{hrs}$ for proper soaking. After, that it was cleaned with distilled water till neutral $\mathrm{pH}$. Then the sample was dried at $100^{\circ} \mathrm{C}$ for $24 \mathrm{hrs}$. This dried sample was again carbonized at $450^{\circ} \mathrm{C}$ for $2 \mathrm{hrs}$ in a muffle furnace and then cooled to room temperature. In this way, chemically activated rice husk was prepared and represented as CARH.

\section{Methylene blue number}

Methylene blue number is defined as the milligram of methylene blue dye adsorbed by $1 \mathrm{~g}$ dried activated carbon. It is a measure of the mesopore content in the activated carbon. The amount of methylene blue adsorbed from each was calculated by using equation 1 , where, $C_{o}$ is the concentration of methylene blue solution $(\mathrm{mg} / \mathrm{L})$ at starting time $(\mathrm{t}=0), \mathrm{C}_{\mathrm{e}}$ is the concentration of methylene blue solution at equilibrium time $(\mathrm{mg} / \mathrm{L})$ which can be calculated by equation $2, \mathrm{~V}$ is the volume of the solution in liter and $\mathrm{M}$ is the mass of the adsorption in $\mathrm{g}$. To determine the methylene blue number, the Langmuir model has been applied. In this model, $\mathrm{q}_{\mathrm{eq}}$ plot is made as a function of $\mathrm{C}_{\mathrm{e}}$. The Langmuir parameters $\left(\mathrm{q}_{\max }\right.$ and $\mathrm{K}$ ) were obtained by a least square fitting regression method.

$$
\begin{aligned}
C_{e} & =\frac{\text { Absorbance }}{\text { Slope }} . \\
\mathrm{q}_{\mathrm{eq}} & =\frac{\mathrm{C}_{\mathrm{o}}-\mathrm{C}_{\mathrm{e}}}{\mathrm{M}} \times \mathrm{V}
\end{aligned}
$$

\section{Iodine number}

Iodine number is the milligram of iodine adsorbed by $1 \mathrm{~g}$ of activated carbon from a $0.1 \mathrm{~N}$ iodine solution when the equilibrium iodine concentration is exactly $0.002 \mathrm{~N}$. Iodine number is an indication of micropore content in activated carbon ( $\left(0-20 \mathrm{~A}^{0}\right.$ or up to $\left.2 \mathrm{~nm}\right)$ by adsorption of iodine from solution. The concentration of iodine in the solution was then calculated from the total volume of sodium thiosulphate used by using equation 3.

$$
\begin{aligned}
& \mathrm{X} / M=\left\{\left(N_{I} \times 126.93 \times V_{I}\right)-\left[\left(V_{I}+V_{H C l}\right) / V_{F}\right] \times\right. \\
& \left.\left(N_{N a_{2} S_{2} O_{3}} \times 126.93\right) \times V_{N a_{2} S_{2} O_{3}}\right\} / \mathrm{Mc}
\end{aligned}
$$

where,

$N_{I}=$ Normality Iodine solution,

$V_{I}=$ Added volume of iodine solution,

$V_{H C l}=$ Added volume of $5 \% \mathrm{HCl}$,

$V_{F}=$ Filtrate volume used in titration,

$\mathrm{N}_{\mathrm{Na}_{2} \mathrm{~S}_{2} \mathrm{O}_{3}}=$ Normality sodium thiosulfate solution,

$V_{\mathrm{Na}_{2} \mathrm{~S}_{2} \mathrm{O}_{3}}=$ Consumed volume of sodium thiosulfate solution,

$\mathrm{M}_{\mathrm{C}}=$ Mass of activated carbon .

\section{Determination of adsorption isotherm}

In order to evaluate adsorption capacity of as prepared activated carbon, adsorption isotherms were obtained. Here, Langmuir and Freundlich isotherm model have been applied and the values were then obtained by using the equation 4-8.

\section{Langmuir isotherm}

Langmuir isotherm purposes that monolayer adsorption occur on solid surface with identical homogenous sites. Once the active sites are covered with dye molecules, no further adsorption takes place. Langmuir constant can be obtained by using equation 4.

$$
\mathrm{Q}_{\mathrm{e}}=\frac{\mathrm{Q}_{\mathrm{m}} \mathrm{bC}}{1+\mathrm{bC}_{\mathrm{e}}}
$$

The linear form of Langmuir expression is expressed as;

$\frac{\mathrm{C}_{\mathrm{e}}}{\mathrm{q}_{\mathrm{e}}}=\frac{1}{\mathrm{Q}_{\mathrm{m}} \mathrm{b}}+\frac{1}{\left(\mathrm{Q}_{\mathrm{m}}\right)} \mathrm{C}_{\mathrm{e}}$

where, 
$\mathrm{C}_{\mathrm{e}}=$ equilibrium concentration of dye solution (mg/L),

$\mathrm{Q}_{\mathrm{e}}=$ equilibrium capacity of dye on the adsorbent (mg/g),

$\mathrm{Q}_{\max }=$ adsorption capacity of the adsorbent $(\mathrm{mg} / \mathrm{g})$, and

$\mathrm{b}=$ Langmuir adsorption constant.

The essential feature of Langmuir adsorption isotherm can be expressed in terms of dimensionless constant called separation factor or equilibrium parameter $\left(\mathrm{R}_{\mathrm{L}}\right)$ which is obtained by equation 6 .

$\mathrm{R}_{\mathrm{L}}=$

$\frac{1}{1+\mathrm{bC}_{\mathrm{o}}}$.

where,

$\mathrm{C}_{\mathrm{o}}=$ Initial concentration $(\mathrm{mg} / \mathrm{L})$

$\mathrm{b}=$ Langmuir constant

$\mathrm{R}_{\mathrm{L}}$ indicates the shape of isotherm and provides the idea of favorability of adsorption. If the RL value is greater than one, adsorption will be unfavorable. Adsorption is favorable only when RL less than one and greater than zero.

\section{Freundlich isotherm}

It is used for the non-ideal sorption that involves heterogeneous surface energy system and is expressed as equation 7 .

$$
\mathrm{Q}_{\mathrm{e}}=\mathrm{K}_{\mathrm{F}} \mathrm{C}_{\mathrm{e}^{\frac{1}{\mathrm{n}}}}
$$

The linear form can be written as;

$\log \mathrm{q}_{\mathrm{e}}=\log \mathrm{K}_{\mathrm{F}}+\left(\frac{1}{\mathrm{n}}\right) \cdot \log \mathrm{C}_{\mathrm{e}}$

where, $\mathrm{K}_{\mathrm{F}}$ and $\mathrm{n}$ (dimensionless constants) are the Freundlich adsorption isotherm constants, $\mathrm{K}_{\mathrm{F}}$ indicates adsorption capacity and $\mathrm{n}$ indicates adsorption intensity. As the value of $\mathrm{K}_{\mathrm{F}}$ increases the adsorbent capacity of adsorbent also increases. The slope $1 / \mathrm{n}$ ranging between 0 and 1 , is favorable adsorption condition.

\section{Determination of surface area}

Surface area of prepared activated carbon was obtained using Langmuir isotherm plot and calculated by using following in equation 9 .

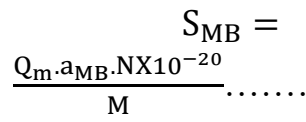

where,

$\mathrm{S}_{\mathrm{MB}}=$ Surface area

$\mathrm{Q}_{\mathrm{m}}=$ Maximum loading
$\mathrm{a}_{\mathrm{MB}}=$ Cross section area of one molecule of $\mathrm{M} \mathrm{B}=$ $197.2 \mathrm{~A}^{\mathrm{o} 2}$

$\mathrm{N}=$ Avogadro's $\mathrm{No}=6.023 \times 10^{23}$

$\mathrm{M}=$ Molecular weight of $\mathrm{MB}=319.84 \mathrm{~g} \mathrm{~mol}^{-1}$

\section{Results and Discussion}

Preparation of raw rice husk (RRH) and chemically activated rice husk (CARH)

Powder form of raw rice husk (RRH) and chemically activated rice husk (CARH) was prepared and is shown in Fig. 2.
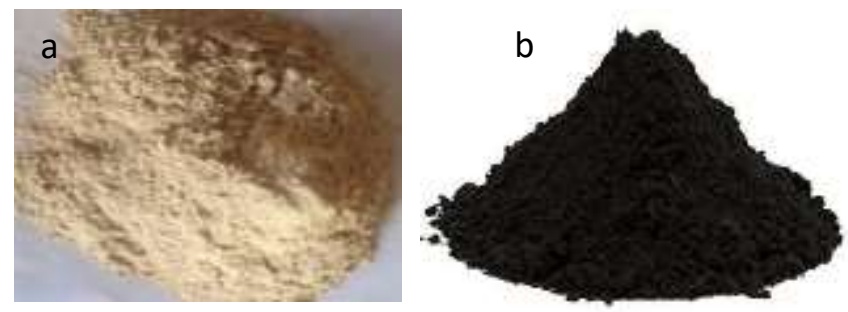

Fig. 2: (a) Raw Rice Husk and (b) Chemically Activated Rice Husk.

\section{Characterization of adsorbents}

\section{X-ray diffraction (XRD)}

X-ray diffraction analysis of the sample was carried out in order to determine the degree of crystallinity or amorphous nature of the activated carbons. The X-ray diffraction of raw rice husk (RRH) and chemically activated rice husk (CARH) is shown in Fig. 3.

In Fig. 3, pattern $\mathbf{a}$ is the diffraction pattern of RRH where one can see a distinct peak at $24^{\circ} 2 \theta$ which shows the amorphous nature although, it has some local crystalline structure with high conjugated aromatic compounds. Similarly small peaks could also be observed at $35^{\circ}$ and $45^{\circ} 2 \theta$ indicating semi crystalline cellulose structure [18].

The pattern $\mathbf{b}$ in Fig. 3, is the diffraction pattern of CARH. The peak in between $20^{\circ}$ to $30^{\circ} 2 \theta$ indicates the crystalline silicon oxide phase in the tetragonal system (JCPDF file no.01-082-1554) [19]. In comparison to pattern $\mathrm{a}$, pattern $\mathrm{b}$ have humplike crystalline peaks or absence of sharp peak. Such a 
diminishing of peak may be due to phosphoric acid activation.

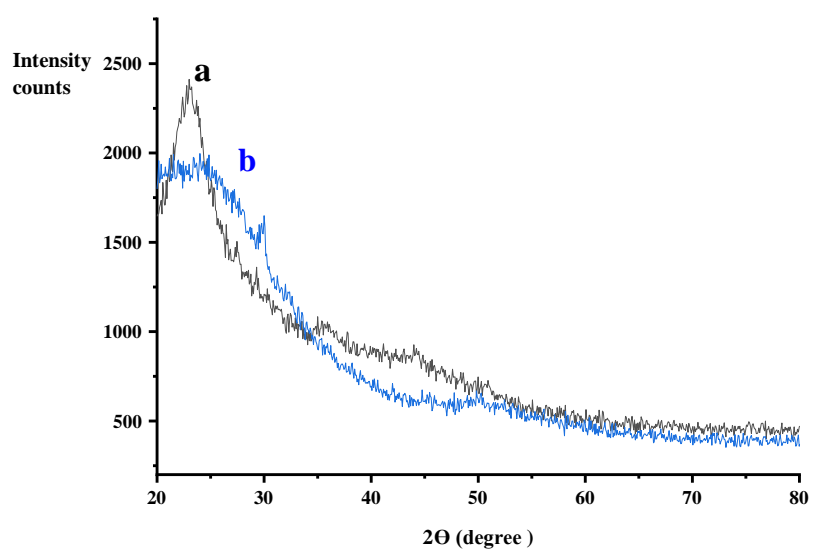

Fig. 3: XRD pattern of (a) RRH and (b) CARH.

\section{Fourier transforms infrared spectroscopy (FTIR)}

The FTIR spectra of RRH is shown in Fig. 4(a) which indicates the presence of $-\mathrm{OH}$ stretching vibration or Si-OH group at around $3724 \mathrm{~cm}^{-1}$. Small band around $2910 \mathrm{~cm}^{-1}$ represents $\mathrm{C}-\mathrm{H}$ stretching of alkanes and stretching aliphatic bond of $-\mathrm{CH},-\mathrm{CH}_{2},-\mathrm{CH}_{3}$ was obtained at $2341 \mathrm{~cm}^{-1}$. The band at $1500 \mathrm{~cm}^{-1}$ to $1750 \mathrm{~cm}^{-1}$ was noted and represents $\mathrm{C}=\mathrm{C}$ stretching of alkenes and aromatic as well as $\mathrm{C}=\mathrm{O}$ stretching of aromatic group [20].

At around $1039 \mathrm{~cm}^{-1}$, bending vibration of $-\mathrm{CH}_{3}$ group or stretching vibration of $\mathrm{Si}-\mathrm{O}-\mathrm{Si}$ bond of siloxane. The band around (450-800) $\mathrm{cm}^{-1}$ indicate bending vibration of $\mathrm{Si}-\mathrm{O}$ bond from amorphous silica.

Similarly, Fig. 4(b) shows the FTIR spectra of CARH. The band at $3716 \mathrm{~cm}^{-1}$ was found to be weaker in comparison to raw rice husk which was broader which implies dehydration of water. The band at 3000 to $2500 \mathrm{~cm}^{-1}$ is due to $-\mathrm{C}-\mathrm{H}$ stretching vibration, was completely diminished. At around $1576 \mathrm{~cm}^{-1}$ a weak band of $\mathrm{C}=\mathrm{C}$ aromatic groups which may be due to partial modification of husk texture during impregnation process. Likewise some changes in band could be observed at around $1086 \mathrm{~cm}^{-1}$ indicates the bending vibration of $-\mathrm{CH}_{3}$ group or stretching vibration of $\mathrm{Si}-\mathrm{O}-\mathrm{Si}$ bond of Siloxane. The band observed at the region lower than $1000 \mathrm{~cm}^{-1}$ can be attributed to compounds with aromatic ring. The band at $450-800 \mathrm{~cm}^{-1}$ is assigned to bending vibration of $\mathrm{Si}-\mathrm{O}$ bond from amorphous silica and was found to be less intense which may be due to modification of the carbon by phosphoric acid activation [20].

\section{Determination of methylene blue number and iodine number}

Porosity was determined by Methylene Blue Number and Iodine Number. The methylene blue number and iodine number of RRH and CARH are presented in Table 1 and Table 2.

Table 1: Methylene Blue Number of RRH and CARH.

\begin{tabular}{ccc}
\hline S.N & Sample & $\begin{array}{c}\text { MethyleneBlue } \\
\text { Number(mgig) }\end{array}$ \\
\hline 1. & RRH & 83 \\
2. & CARH & 99 \\
\hline
\end{tabular}

Table 2: Iodine Number of RRH and CARH.

\begin{tabular}{ccc}
\hline S.N & Sample & $\begin{array}{c}\text { lodineNumber } \\
\text { (mgfg) }\end{array}$ \\
\hline 1. & RRH & 415.1 \\
2. & CARH & 716.3 \\
\hline
\end{tabular}

Prepared sample implies that large number of micropores on the surface rather than mesopores i.e. iodine number is found to be greater than methylene blue number. It may be due to easy breakdown of amorphous polymers like lignin and hemicelluloses which produce micropores and crystalline form like cellulose which produce mesoporosity. In case of RRH porosity was low as indicated by low surface area (Table 3 ) but in 
a

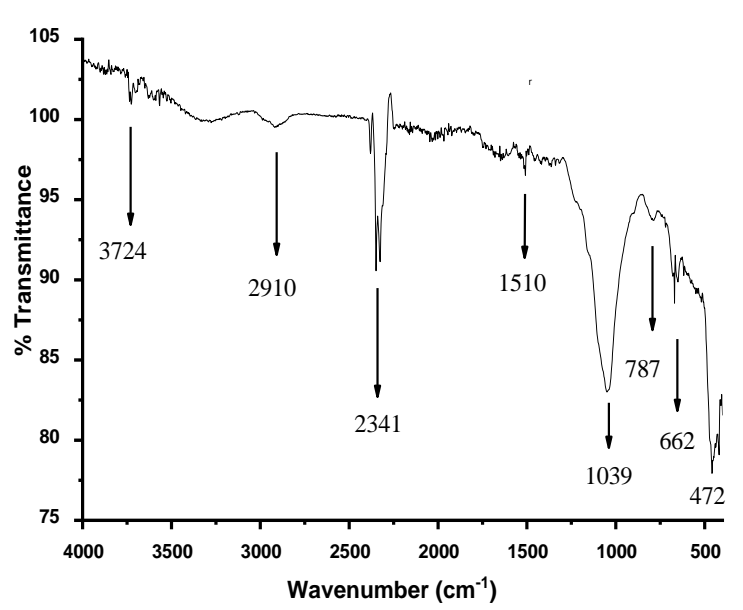

b

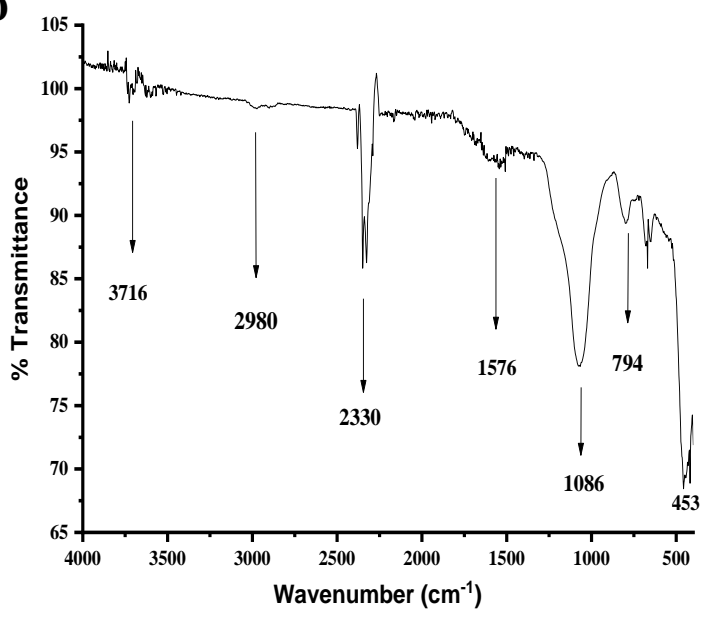

Fig. 4: FTIR spectra of (a) RRH and (b) CARH.

CARH, which was carbonized and activated chemically, there was loss of volatile compounds, dehydration of lignocellulose materials as well as cleavage of the bond takes place. As a consequence, porosity developed.

\section{Determination of surface area}

The surface area of RRH and CARH were calculated using equation 9 and are tabulated in Table 3. The surface area of CARH was found to be $531 \mathrm{~m}^{2} / \mathrm{g}$ which was higher than RRH. It may be due to loss of volatile compounds, dehydration of lignocellulosic materials and cleavage of the bond during chemical activation and carbonization.

Table 3: Surface area of RRH and CARH

\begin{tabular}{ccc}
\hline S.N & Sample & $\begin{array}{c}\text { SurfaceArea } \\
\left(\mathrm{m}^{2} / \mathrm{g}\right)\end{array}$ \\
\hline 1. & RRH & 206 \\
2. & CARH & 531 \\
\hline
\end{tabular}

\section{Adsorption isotherms}

In order to evaluate adsorption behavior of prepared samples, different Isotherm models have been fitted.

\section{Langmuir isotherm of RRH and CARH}

Langmuir isotherm of raw rice husk (RRH) and chemically activated rice husk (CARH) was obtained by plotting ce/qe verses ce which is shown in Fig. 5.a and Fig. 5.b respectively. Graph was found to be linear and fitted with Langmuir model. The results or Langmuir parameters which were obtained are presented in Table 4.
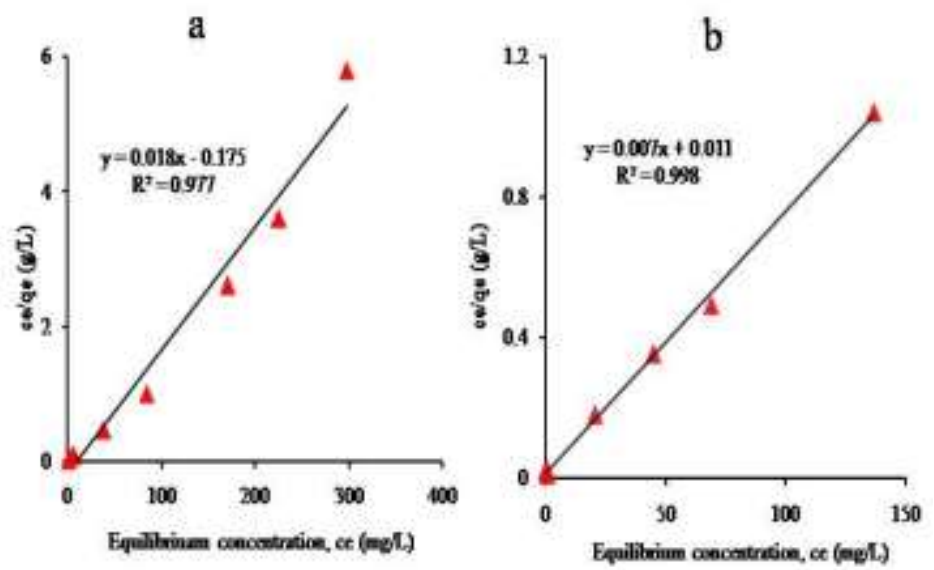

Fig. 5: Langmuir Isotherm of (a) RRH and (b) CARH. 
Table 4: Langmuir parameters.

\begin{tabular}{ccccc}
\hline Adsorbents & \multicolumn{4}{c}{ Langminir lsotherm } \\
\hline & B(L/mg) & Qm(mgg) & $\mathrm{R}^{2}$ & $\mathbf{R}_{\mathbf{L}}$ \\
\hline RRH & -0.3 & 55.0 & 0.977 & -0.01 \\
CARH & 1.82 & 142.9 & 0.998 & 0.3 \\
\hline
\end{tabular}

\section{Freundlich isotherm for RRH and CARH}

Freundlich isotherm of raw rice husk (RRH) and chemically activated rice husk (CARH) was obtained by plotting $\log \mathrm{q}_{\mathrm{e}}$ verses $\log \mathrm{c}_{\mathrm{e}}$ and is shown in Fig. 6 (a) and (b).
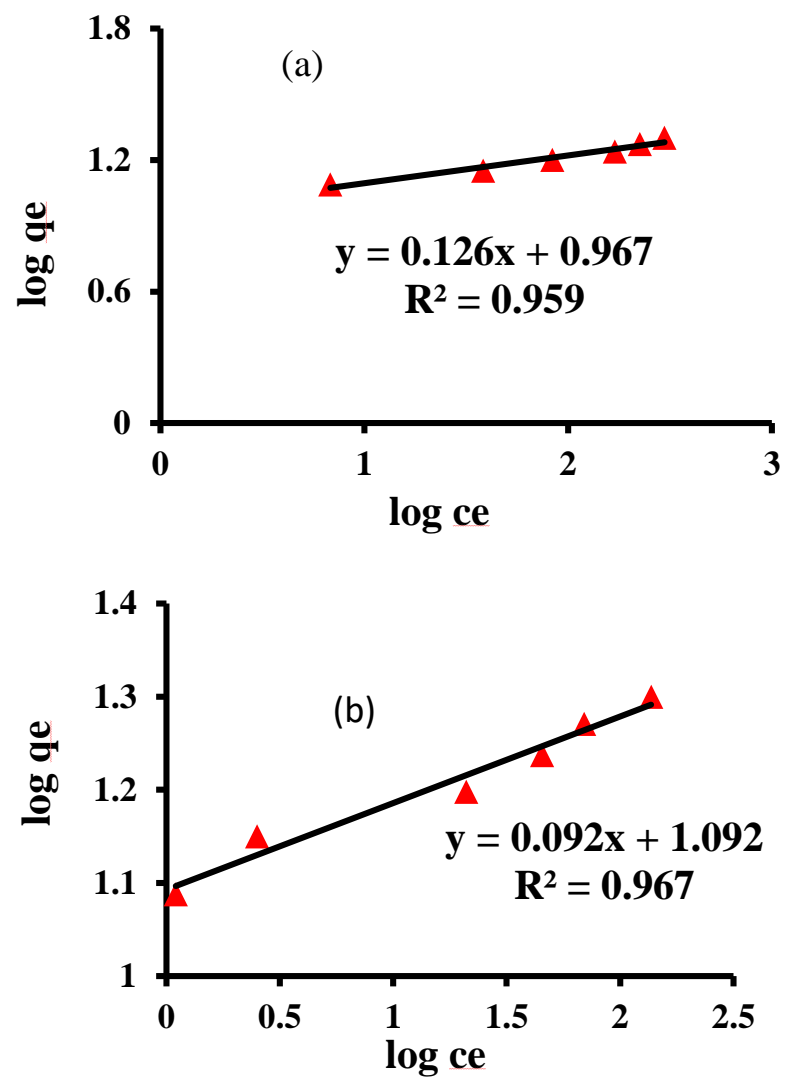

Fig. 6: Freundlich Isotherm of (a) RRH and (b) $\mathrm{CARH}$

The Freundlich parameters obtained are presented in Table 5.
Table 5: Freundlich parameters.

\begin{tabular}{ccccc}
\hline Adsorbents & \multicolumn{5}{c}{ Freandlich Isothem } \\
& 1 in & n & K $_{\mathbf{F}}$ (mgfg) & R $^{2}$ \\
& & & & \\
\hline RRH & 0.126 & 7.93 & 1.857 & 0.959 \\
CARH & 0.092 & 10.87 & 1.848 & 0.967 \\
\hline
\end{tabular}

From Table 4 and Table 5, the correlation coefficient $\mathrm{R}^{2}$ values of Langmuir isotherm and Freundlich isotherm were evaluated. Langmuir isotherm of CARH was found to be 0.998 and of RRH was 0.977 which was higher than the value obtained from Freundlich isotherm i.e. for CARH it was 0.967 and for RRH it was 0.959 . It shows that Langmuir adsorption isotherm model was found to be best fitted.

Table 6: Comparison of adsorption capacities of various activated carbons

\begin{tabular}{|c|c|c|}
\hline Precursors & $\begin{array}{c}\text { Adsoptioncapacity } \\
\text { Q (mg/g) }\end{array}$ & \\
\hline Bananastalkwaste & 243.90 & [21] \\
\hline Modified ricestraw & 208.33 & {$[22]$} \\
\hline Salsolarerniculataplant & 130 & [23] \\
\hline Pumpkinseadhull & 141.92 & [24] \\
\hline Pineapplestem & 119.05 & [25] \\
\hline Coffeehnsk & 90.1 & [26] \\
\hline Teaweste & 85.16 & [27] \\
\hline CCRH & 143 & Presentwork \\
\hline
\end{tabular}

The results revealed that CARH has solid surface with identical homogenous sites where monolayer 
adsorption took place. The active sites were first covered with dye molecules and there were no further adsorption occurred. The maximum adsorption capacity of CARH was found to be 143 $\mathrm{mg} / \mathrm{g}$ which was found to be higher than RRH which was also supported by high surface area of CARH (Table 3). Similarly, the equilibrium parameter $\mathrm{R}_{\mathrm{L}}$ value was found to be less than one which revealed the favorability of adsorption. The adsorption capacity of CARH was compared with literature values and found to be good (Table 6).

\section{Conclusion}

It has been concluded that activated carbon can be prepared from low cost laboratory fabricated open type carbonizer. For the preparation of activated carbon, rice husk was used as a precursor. Prepared materials were characterized by $\mathrm{MB}$, IN, surface area, XRD and FTIR spectroscopy. XRD pattern of $\mathrm{RRH}$ and CARH showed the amorphous with some crystalline nature of the materials. Similarly, FTIR spectra of RRH and CARH showed the presence of siloxane bond, hydroxyl, carbonyl and $\mathrm{Si}-\mathrm{O}$ bond from amorphous silica. The adsorption behavior of prepared materials were studied and results revealed that Langmuir model was best fitted in both sample as indicated by the correlation coefficient $\mathrm{R}^{2}$ value. The dimensionless separation factor $\mathrm{R}_{\mathrm{L}}<1$ indicating a favorable adsorption condition for CARH. Hence, low cost laboratory fabricated open type carbonizer is good for the synthesis of activated carbon from waste product.

\section{References}

[1] H. Zhang, Y. Yanl and L. Yang, Preparation of activated carbons from sawdust by chemical activation, Ads. Sci. Tech. 26 (2008) 533-543.

[2] D. Shrestha, S. Maensiri, U. Wongpratat, S.W. Lee, A. Rajbhandari (Nyachhyon), Shorearobusta derived activated carbon decorated with manganese dioxide hybrid composite for improved capacitive behaviors, J. Env. Chem. Eng. 7 (2019)103-227.
[3] N. Yahaya, M. Latiff, I. Abustan and M.A. Ahmad, Effect of preparation conditions of activated carbon prepared from rice husk by zinc chloride activation for the removal of $\mathrm{Cu}$ (II) from aqueous solution, Int. J. Eng. Tech.10 (2010) 28-32.

[4] Q. Cao, K.C. Xie, Y.K. Lv and W.R. Bao, Process effects on activated carbon with large specific surface area from corn cob, Biores. Tech. 97(2006) 110-115.

[5] B.S. Girgis, L.B. Khalil and T.A.M. Tawfic, Activated carbon from Sugarcane bagasse by carbonization in presence of inorganic acids, J. Chem. Tech. Biotech. 61(1994) 87-92.

[6] B. Amarasingle, and R. Williams, Tea waste as a low cost adsorbent for the removal of $\mathrm{Cu}$ and $\mathrm{Pb}$ from wastewater, Chem. Eng. J. 132 (2007) 299-309.

[7] M. Plaza, C. Pevida, C. Martin, J. Fermoso, J. Pis and F. Rubiera, Developing almond shell- derived activated carbons as $\mathrm{CO}_{2}$ adsorbents, Sep. Purif. Tech. 71 (2010) 102-106.

[8] J. Laine and S. Yunes, Effect of the preparation method on the pore size distribution of activated carbon from coconut shell, Carbon. 30 (1992) 601604.

[9] E. Demirbaş, M. Kobya, S. Oncel and S. Şencan, Removal of $\mathrm{Ni}$ (II) from aqueous solution by adsorption onto hazelnut shell activated carbon: equilibrium studies, Bioresour. Tech. 84 (2002) 291-293.

[10] M.L. Martínez, M.M. Torres, C.A. Guzmán and D.M. Maestr, Preparation and characteristics of activated carbon from olive stones and walnut shells, Ind. Crops Prod. 23 (2006) 23- 28.

[11] M.O. Kobya, E. Demirbas, E. Senturk and M. Ince, Adsorption of heavy metal ions from aqueous solutions by activated carbon prepared from apricot stone, Bioresour. Tech. 96 (2005) 15181521.

[12] M.O. Marín, C.F. González, A.M. García, and V.G. Serrano, Preparation of activated carbon from cherry stones by chemical activation with $\mathrm{ZnCl}_{2}$, App. Surf. Sci. 252 (2006) 5967-5971.

[13] K.Y. Foo and B.H. Hameed, Utilization of rice husks as a feedstock for preparation of activated carbon by microwave induce $\mathrm{KOH}$ and $\mathrm{K}_{2} \mathrm{CO}_{3}$ activation, Bioresour. Tech.102 (2011) 9814-9817. 
[14] P. Chindaprasirt, P. Kanchanda A. Sathonsaowaphak \& H.T. Cao, Rice husk an overview, science direct topics, 2007.

[15] A.T. Belonio, Design and evaluation of a drumtype rice hull carbonizer and manually -operated molder for bio coal fuel production and for agriculture application, Rice Tech. Bull. 47 (2003) 1-6.

[16] F.R. Reinoso and M.M. Sabio, Role of chemical activation in the development of carbon porosity, Coll. Surf. 241 (2004) 15-25.

[17] V.K. Gupta and Suhas, Application of low cost adsorbents for dye removal-A review, J. Env. Manag. 90 (2009) 2313-2342.

[18] H.I. Riyap, C.N. Bewa, C. Banenzoue, H.K. Tachakoute, C.H. Ruscher, E. Kamsue, M.C. Bignozzi and C. Leonelli, Microstructure and mechanical, physical and structural properties of sustainable lightweight metakaolin-based geopolymer cements and mortars employing rice husk, J. As. Cers. Soc. 7(2019)199-212.

[19] Z. Emdadi, N. Asim, M.A. Yarmo and K. Sopian, Effect of chemical treatments of rice husk (RH) water absorption property, Int. J. Chem. Eng. App., 6 (2015) 4.

[20] M. Bardalai and D.K. Mahanta, Characterization of rice husk through X-ray diffraction, scanning electron microscope and Fourier transform infrared analysis, Int J.Innu. Res. Sc. Eng. 2(2016) 472-479.

[21] B.H. Hameed, D.K. Mahmoud and A.L. Ahmad, Sorption equilibrium and kinetics of basic dye from aqueous solution using banana stalk waste, J. Hazard. Mater. 158 (2008) 499-506.

[22] R. Gong, Y. Jin, J. Chen, Y. Hu and J. Sun, Removal of basic dyes from aqueous solution by sorption on phosphoric acid modified rice straw, Dyes Pigments. 73 (2007) 332-337.

[23] B. Bestani, N. Benderdouche, B. Benstaali, M. Belhakemand A. Addou, Methylene blue and iodine adsorption onto an activated desert plant, Bioresour. Technol. 82 (2008) 79-85.

[24] B.H. Hameed and M.I. El-Khaiary, Removal of basic dye from aqueous medium using a novel agricultural waste material: pumpkin seed hull, J. Hazard. Mater.155 (2008) 601-609.

[25] B.H. Hameed, R.R. Krishni and S.A. Sata, A novel agricultural waste adsorbent for the removal of cationic dye from aqueous solution, J. Hazard. Mater. 162 (2009) 305-311.

[26] L.S. Oliveira, A.S. Franca, T.M. Alves and S.D.F. Rocha, Evaluation of untreated coffee husks as potential biosorbents for treatment of dye contaminated waters, J. Hazard. Mater. 155 (2008) 507-512.

[27] M.T. Uddin, M.A. Islam, S. Mahmud and M. Rukanuzzaman, Adsorptive removal of methylene blue by tea waste, J. Hazard.Mater.161 (2009) 5360. 